Año LXXXI. urtea $276-2020$

Enero-abril Urtarrila-apirila

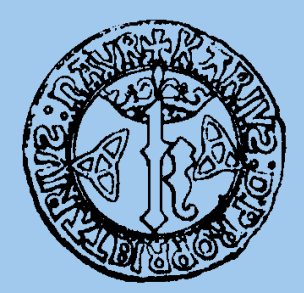

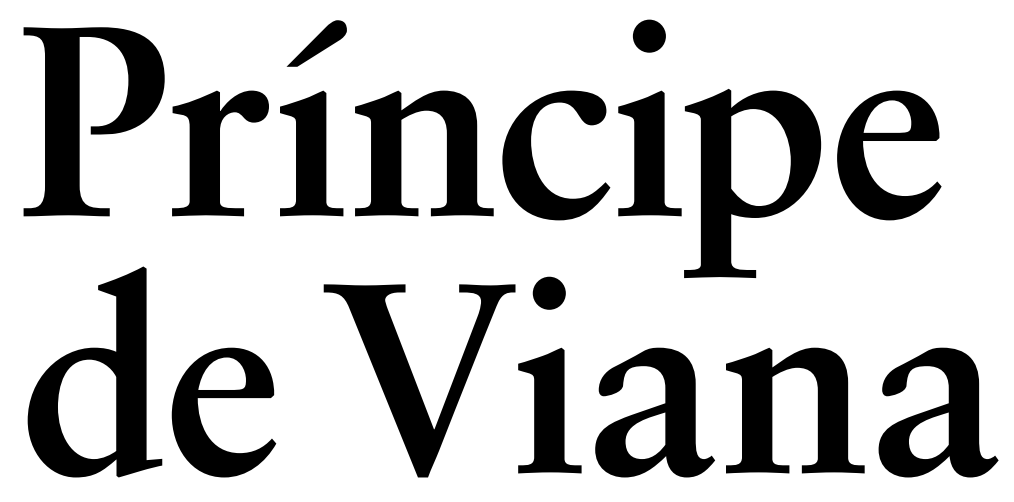

SEPARATA

Viento a favor: talento

y carácter. Navarra en

la industria audiovisual

(2019)

Marga Gutiérrez Díez 


\section{Sumario / Aurkibidea}

\section{Príncipe de Viana}

Año LXXXI • n. ${ }^{\circ} 276$ • enero-abril de 2020

LXXXI. urtea $\cdot 276$. zk. 2020 ko urtarrila-apirila

\section{LITERATURA}

La realidad literaturizada y la ira contra la religión católica y el obispo de Pamplona en el «Libro segundo» de La familia de Errotacho, de Pío Baroja Miguel Ángel García de Juan

\section{HISTORIA}

La represión del protestantismo en el tribunal inquisitorial de Calahorra-Logroño (1550-1610)

Marcos Gómez García

Entre España y México, la libertad. El embajador Félix Gordón Ordás y su evocación de la figura del navarro Javier Mina en el marco de la guerra civil española

Un discurso inédito de Víctor Sainz de Robles en 1867

Emilio Cervantes Ruiz de la Torre

Política social y autogobierno en el núcleo de la conspiración carlista antirrepublicana

La botica del monasterio cisterciense de Santa María de La Oliva (Navarra) Juan Manuel Garde Garde

\section{DERECHO / ZUZENBIDEA}

Un debate sobre la Ley de 1841: Navascués, la Diputación, «El Mosquerino» y Ezquerra 


\section{Sumario / Aurkibidea}

\section{LOS TRABAJOS Y LOS DÍAS DEL AÑO 2019 / 2019ko LANAK ETA EGUNAK}

Tesis doctorales sobre temática navarra de ciencias humanas, sociales y jurídicas, leídas en 2019

(Según la Base de datos Teseo del Ministerio de Educación)

Medio siglo de Fontes Linguae Vasconum

Ekaitz Santazilia

Actividades en torno al cincuenta aniversario de la revista Cuadernos de

Etnología y Etnografía de Navarra

David Mariezkurrena

Autores y autoras navarras en castellano, año 2019

Mikel Zuza Viniegra

Nafar egileen euskarazko liburuak 2019an

Ángel Erro Jiménez

Viento a favor: talento y carácter. Navarra en la industria audiovisual (2019)

Marga Gutiérrez Díez

Tensión de rotura. Un panorama expositivo de 2019

Mireya Martín Larumbe

Hiriartea: crónica de un proyecto frustrado por una mala práctica en las políticas culturales

Arantza Santesteban

De escalas, tiempos y cultura: grado en Historia y Patrimonio por la UPNA

Fernando Mendiola Gonzalo, Miguel R. Wilhelmi

Investigación y difusión del patrimonio cultural navarro en la Universidad de

Navarra (2019)

Yolanda Cagigas Ocejo

Entrevista a Tomás Yerro Villanueva. Premio Príncipe de Viana de la Cultura 2019

Alicia Ezker Calvo

Si mi padre volviera, yo sería su escudero. Qué gran caballero era

Tomás Yerro. (Discurso)

Currículums

Analytic Summary

Normas para la presentación de originales / Idazlanak aurkezteko arauak /

Rules for the submission of originals

6 Príncipe de Viana (PV), 276, urtarrila-apirila, 2020 ISSN: 0032-8472 | ISSN-e: 2530-5824 | ISSN-L: 0032-8472 


\title{
Viento a favor: talento y carácter. Navarra en la industria audiovisual (2019)
}

\author{
Marga GuTiÉRREZ DíEZ \\ Gerente del CLAVNA (febrero de 2017 a marzo de 2018) \\ marga@laescenadeljardin.com
}

DOI: https://doi.org/10.35462/pv.276.13

El mar es tan profundo en la calma

como en la tempestad

John Donne

\section{EL PUERTO}

Escribir la calma desde la tempestad supone un esfuerzo casi de guion. Parece ficción esa delicada manera de reunir mentiras para que parezcan verdad, ahora más notable con la mirada hacia atrás. Acciones, proyectos, resultados, números y porcentajes se disipan tras la pandemia. Doble esfuerzo para recordar y poner sobre la mesa el trabajo de empresas y profesionales que en 2019 sentaron las bases de un negocio e industria de un territorio que ha hecho un esfuerzo por posicionarse en el entramado audiovisual.

Una mezcla de talento y carácter propio marcado por políticas enfocadas en la industria que incluye, en números, a 2370 empresas en torno a las industrias creativas y digitales, con 6350 trabajadores y trabajadoras, y suponen el 4,4\% del VAB y el 2,5\% del empleo de la Comunidad Foral. De ellas, unas cien empresas corresponden al sector audiovisual, televisión y radiodifusión, que cuenta con 350 puestos de trabajo. Para el consejero Ayerdi, en el acto de inauguración de Conecta Fiction 2019 -evento realizado en Pamplona y de referencia en Europa para la financiación y la coproducción de contenidos de televisión- el audiovisual es un sector "prioritario» en términos de inversiones y recordó que forma parte de «las industrias creativas y digitales», uno de los seis ámbitos estratégicos de desarrollo económico en la Estrategia de Especialización de Navarra. 
La industria contó con impulsos públicos, iniciativas privadas y proyectos de ficción y documental remarcables. Con perspectiva y calma revisaremos las estrellas, faros y viento a favor que nos dejó el 2019. Partimos.

\section{RUTA Y MAPA ESTELAR}

NICDO sigue siendo patrón de barco en muchos de los movimientos y acciones del audiovisual navarro. En 2019 podemos destacar:

\section{Filmoteca de Navarra}

La Filmoteca de Navarra, que se encuentra a un año de su décimo aniversario, sigue apostando por su misión inicial: acoger el archivo fílmico, una sala técnica y una sala de proyecciones, además de los fondos bibliográficos y audiovisuales de temática cinematográfica tanto en libre acceso como en depósitos.

En el ámbito de la difusión cinematográfica, en su sala de proyecciones con 176 butacas se programan habitualmente tres sesiones semanales (miércoles, jueves y viernes), fundamentalmente dedicadas al cine clásico y al cine relacionado con Navarra.

Destaca uno de los ciclos consolidados: el denominado «Cine imprescindible». Por octavo año consecutivo, la cinemateca navarra organizó esta recogida y oferta de filmes para el mejor entendimiento del séptimo arte con películas como Rebelde sin causa, Blade Runner, una coproducción norteamericana que supuso la primera incursión del cineasta polaco Roman Polanski en América (El baile de los vampiros), la muy personal adaptación del drama alemán de Heinrich Boll, El honor perdido de Katharina Blum a cargo de su compatriota Volker Schlöndorff y su esposa Margarethe von Trotta, o Todas las mañanas del mundo ambientada en el mundo musical del siglo XVII, así como proyectos como Big Fish (Tim Burton, 2003) y Rebelde (Kim Nguyen, 2012).

Napar (Asociación de Productoras y Profesionales del Audiovisual en Navarra), en colaboración con la Filmoteca de Navarra, proyectó en la sección «NAPAR en la Filmoteca» trabajos de sus asociados (productoras audiovisuales de Navarra), tanto finalizados como en proceso. Se trata de un proyecto novedoso para mostrar el papel del propio cine y de los cineastas como figuras clave en el devenir del propio territorio, como testimonios de la contemporaneidad y también como artistas, creadores, que marcan e influyen en la propia historia.

Otro potencial son las «Sesiones especiales», fuera de los programas habituales de la Filmoteca, dedicadas a ámbitos tan opuestos como el homenaje cinéfilo o la infografía con títulos como Sílbala otra vez, J. J., The Blue Eyes, Whistler, ¿Qué bello es vivir! Jainkoak ez dik barkatzen / Dios no me perdona. Además, hay que resaltar el programa BAFTA Shorts 2018 o la muestra de premios Malofiej. En 2019 también incluyeron destacados proyectos del Festival de Cine de Hendaya o el VI Concurso Europeo de Creación Audiovisual «CTL 59 segundos». 
Como referente en Navarra el Festival Punto de Vista tiene su espacio para asegurar el impulso del cine documental en Pamplona más allá de las fechas exclusivas del festival en febrero. Las sesiones se celebraron habitualmente los jueves últimos de cada mes.

También en su 13. ${ }^{a}$ edición, Ekozinemaldia, festival de cine y deuda ecológica organizado por Ekologistak Martxan y Mugarik Gabeko Ingeniaritza/Ingeniería sin Fronteras, desde su proyecto conjunto TRADENER (Transición Democrática Energética) tuvo representación en Filmoteca, así como en trece pueblos y ciudades de País Vasco.

«In Memoriam» ha tenido triple reconocimiento póstumo hacia Bernardo Bertolucci (El conformista, 1970 y Soñadores, realizado en 2003), hacia la inigualable y especial Agnés Vardá (cuatro sesiones para recordar algunos de sus filmes más representativos (Cléo de 5 a 7, Sin techo ni ley, Los espigadores y la espigadora, Dos años después, Caras y lugares) y, por último, a Stanley Donen.

«Ateneo Presenta» ofreció algunas obras destacadas de Robert Mulligan, Paulino Viota -quien presentó la que fuera su última película, Cuerpo a cuerpo (1982)-, Umberto D, de Vittorio de Sica, o Nubes pasajeras, de Aki Kaurismäki.

Otros ciclos fueron muy bien recibidos por el público como la retrospectiva de HelenaTaberna con títulos tan destacados y reconocibles de la directora navarra como Yoyes, Nagore, La buena nueva o Extranjeras. También tuvieron su lugar ciclos como «Pamplona Negra»; la séptima edición de CIDE («Cine y dentistas») con La mujer preferida, Rio Lobo, Cachorro; "Neurocine» con proyectos como Despertares, 100 metros, El hijo de la novia; "La abogacía en el cine III" con Llamad a cualquier puerta o El inocente; "Arquitectura de cine», Barcelona en dos actos, Mi tío; el ciclo "Con destino la Luna» con títulos como La mujer en la luna, Sueños de un astrónomo, El eclipse: el cortejo entre el sol y la luna, Celebrating Apollo as We, Operación Avalancha; el "Cine palestino" con Invitación de boda, Domicilio privado, Roadmap to Apartheid. Podemos destacar los ciclos "Beltza Weekend», "Cine Ciencia III", "Cines africanos», "Cine de Latinoamérica, BAL 2019», «Zinelur» o «Jean Renoir esencial» con títulos como La gran ilusión, Esta tierra es mía, El sureño, La carroza de oro o French Cancan.

Filmoteca realizó un año más el «Taller de cine para jóvenes» en el que se crean películas rodadas en super $8 \mathrm{~mm}$ que se proyectan al público dentro de la programación o muestras expositivas.

\section{Navarra Film Commission (NFC)}

Diez años de la oficina Film Comission retratan su consolidación. Fue creada por el Gobierno de Navarra en 2009 con el objetivo de facilitar el trabajo a las empresas y profesionales del sector audiovisual que desearan rodar en la Comunidad Foral gestionando labores de desarrollo de los proyectos audiovisuales que se lleven a cabo en la comunidad, atrayendo rodajes al territorio y asesorando y resolviendo consultas relativas al sector. 
Por ello, en septiembre de 2019 se realizó una exposición como homenaje a la diversidad de localizaciones que existen en Navarra y a algunas de las muchas producciones que se han rodado a lo largo de la historia. A través de paneles informativos se resaltaron dieciocho localizaciones en las que se han rodado películas o series, con información sobre la localización, un mapa con su ubicación, información de la producción y rodaje, así como imágenes de la película o serie, una mirada atrás muy representativa en la que se destacaron localizaciones y películas tan conocidas como: Artajona, Robin y Marian; Bardenas, Juego de tronos; Ochagavía, Secretos del corazón; Leitza, Ocho apellidos vascos; Pamplona, Los Japón; Pitillas, Legend n. ${ }^{\circ}$ 17; San Fermín, ¡Fiesta!; Tafalla, Line Walker II; Urbasa, The Sisters Brothers; Uztarroz, Lo nunca visto; Zugarramurdi, Las brujas de Zugarramurdi; Aldatz, Cuando dejes de quererme; Camino de Santiago, The Way; Elizondo, El guardián invisible; Estella, Bajo las estrellas; Gallipienzo, El hombre que mató a Don Quijote; Iranzu, Conquistadores adventvm; y Marcilla, Remember Me.

Film Commission de Navarra sigue a la cabeza como oficina de cine y audiovisual, dentro de la red de Spain Film Comission, para rodajes internacionales, nacionales y locales. Hay que destacar las relaciones dentro del marco SFC con Casa de la India para la introducción de la organización española en los diferentes festivales de referencia del país y en la industria de Bollywood. También ha sido el primero que España estaba representada a través de SFC y en colaboración con ICEX en el mercado audiovisual en China o el encuentro liderado por Spain Film Commission en Los Ángeles (California) en el contexto del American Film Market para el desarrollo de las relaciones comerciales y la atracción de proyectos audiovisuales a territorio entre los principales productores norteamericanos y los productores españoles.

Es reseñable el proyecto, muy demandado por el sector de las industrias culturales, de actualización de su web y su portal https://navarrafilmindustry.com/ generado en colaboración con Napar (Asociación de Productoras Audiovisuales de Navarra) y CLAVNA (Clúster Audiovisual de Navarra). En este portal se pueden encontrar las ayudas públicas, recursos formativos, información sobre incentivo fiscal, permisos de rodaje o localizaciones. De especial importancia para el sector ha sido la Guía Audiovisual de Navarra www.guiaaudiovisualdenavarra.com con un directorio completo y estructurado de empresas y profesionales de la Comunidad Foral de Navarra. Dicha actualización también incluye materiales y folletos de incentivos fiscales para la producción audiovisual en su distribución internacional con nuevas fotografías de rodaje y localizaciones recopiladas a lo largo de los diferentes rodajes sucedidos en Navarra. La nueva reformulación del incentivo permitirá además la inclusión del logotipo de Navarra Film Commission.

NFC colaboró de manera directa con festivales y certámenes relacionados con el sector audiovisual en Navarra para la promoción turística y audiovisual de la comunidad: Certamen de Cortometrajes Navarra Tierra de Cine, NIFF (Navarra International Film Festival), Skimetraje, CTL 59, Lo que viene, Opera Prima, Conecta Fiction y la Gala concurso SciencEkaitza. Así mismo acudió como miembro acreditado a FITUR, European Film Market (Berlín) Series Mania (Lille) Conecta Fiction (Pamplona), Zinemaldi (San Sebastián) y 948 Merkatua (Pamplona) 
En 2019, según datos oficiales de Navarra Film Commission, se rodaron 10 largometrajes de ficción, 6 largometrajes documentales, 47 cortometrajes, 7 series para televisión, 14 spots, 3 videoclips y 10 programas de televisión en el territorio navarro. Siendo el 2019 el año más productivo de los últimos cuatro años. (2016_67 producciones, 2017_76 producciones, 2018_95 producciones, 2019_99 producciones)

\section{Punto de Vista en 2019}

La decimotercera edición del Festival Punto de Vista, organizado por primera vez íntegramente desde NICDO, sociedad pública del Gobierno de Navarra, y promovido por el Departamento de Cultura Deporte y Juventud, volvió a estar liderado por Garbiñe Ortega. Contó con siete grandes apartados: la Sección Oficial, con películas seleccionadas de entre las más de 1160 que se inscribieron desde países de todo el mundo; Retrospectivas, con figuras imprescindibles de la vanguardia, Marcia Hafif y Jonathan Schwartz; Dokbizia, con artistas de diferentes disciplinas para intercambiar su forma de relacionarse con lo real; los Punto de Vista Labs, espacio para el intercambio de saberes y la creación colectiva; los Focos Contemporáneos, sesiones monográficas a través de las cuales Punto de Vista centró su mirada en algunos de los cineastas más relevantes del panorama internacional; las Sesiones Especiales, con programas como el de X Films, el encuentro de cineastas vasco-navarros Paisaia o un ciclo de filmes en Planetario y, por último, el Programa Educativo, que crece para continuar abriendo el Festival a nuevos públicos.

La cifra de público ha sido algo superior a la de la última edición, alcanzando solo en el Palacio de Congresos y Auditorio de Navarra alrededor de 5500 espectadores. Esto se ha traducido en que varias de las más de cincuenta sesiones programadas agotaron las entradas, como fue el caso de las retrospectivas de Jonathan Schwartz, la performance de Niño de Elche Los aires llevan mentiras, el homenaje dedicado a Jonas Mekas, la sesión de cine sonoro de Xabier Erkizia, el programa del viernes de Marie Losier o la sesión de las últimas películas de John Price. El resto de sedes del Festival fueron el Planetario de Pamplona, el Centro de Arte Contemporáneo de Huarte, la Filmoteca Navarra, la Universidad de Navarra, la red Civivox, Civican o Geltoki.

Fue reseñable la participación de profesionales del ámbito del cine: más de doscientos profesionales, entre cineastas, profesorado y programadores y programadoras de festivales como la Berlinale, el Festival de Cine de Locarno o la National Gallery of Art de Washington. También hubo record en el número de estudiantes con acreditación: 140 estudiantes de escuelas de cine, como la ESCAC (Barcelona), la EQZE (Donostia), la ECAM (Madrid), Master LAV (Madrid) o la Universidad Autónoma de Barcelona, han podido asistir y disfrutar del Festival.

Dentro del Palmarés 2019 podemos destacar el Gran Premio Punto de Vista a la Mejor Película, dotado con 10000 euros, para Una luna de hierro de Francisco Rodríguez, Premio Jean Vigo a la Mejor Dirección, dotado con 5000 euros, para Parsi de Eduardo Williams, así como Premio al Mejor Cortometraje, dotado con 3000 euros, para Mum's Cards de Luke Fowler. Otorgados por el prestigioso jurado Erika Balsom, Dennis Lim y 
Eva Sangiorgi. También fue premiado el cine navarro con el Proyecto X Films a Maddi Barber por «Rojo».

Hubo una muestra especial de obra producida por artistas locales. Ikusleak, de Jesús María Palacios; 592 metroz goiti, de Maddi Barber; Ancora Lucciole, de Maria Elorza; y Amor Siempre, de Maider Fernández Iriarte.

\section{Opera Prima de Tudela}

La vigésima edición del Festival de Cine Opera Prima Ciudad de Tudela, cifra redonda y significativa, se celebró en el cine Moncayo con un variado abanico de largometrajes nacionales que constituyen el debut de sus directores y directoras. Los siete largometrajes seleccionados en esta ocasión fueron de temática variada, propuestas de todos los presupuestos posibles y de todos los géneros, componiendo un fiel retrato del «nuevo cine español».

El festival, ampliamente asentado en la ciudad, llena todas sus sesiones y tiene la particularidad de que el público otorga, con sus votaciones, el primer premio del palmarés. Además, estudiantes de secundaria de los centros educativos de Tudela, asistiendo y votando en sesiones matinales, otorgan el premio de la juventud.

El palmarés fue el siguiente: Primer Premio (premio del público) y Premio de la Juventud para Abuelos, de Santiago Requejo, Premio Príncipe de Viana a la mejor dirección para Belén Funes (La hija de un ladrón), que también se llevó el premio especial de Igualdad. Finalmente, el jurado otorgó el Premio Especial a Ojos Negros, de Marta Lallana e Ivet Castelo.

En esta ocasión, con motivo del vigésimo aniversario del festival, por primera vez en su historia, y seguramente por primera vez en la historia de los festivales cinematográficos españoles, el jurado estuvo formado exclusivamente por mujeres: Carla Simón, Neus Ballús, Paola García Costas, Verónica Forqué, Marta Nieto, Toni Acosta, Teresa Font, Sara Vítores y Marina Perezagua. Cineastas, periodistas, escritoras, actrices y una montadora que, con su criterio y saber hacer, también pusieron la nota reivindicativa sobre la presencia de la mujer en la industria audiovisual española.

\section{Generazinema: las ayudas públicas}

En 2019 el Departamento de Cultura y Deporte del Gobierno de Navarra concedió 510000 euros en ayudas a la producción cinematográfica y 15000 euros de ayudas a la distribución e internacionalización, a través de la convocatoria Generazinema 2019. En total fueron diecisiete proyectos, de los que ocho son largometrajes, seis cortometrajes y tres proyectos de producción de largometrajes.

En largometrajes los proyectos seleccionados fueron Campanadas a muerto, de Kanpaiak Abra AIE (100000 euros); 2 urte 4 hilabete, de Labrit Multimedia (24220,32 euros); Surcos, de Escorzo Films SL (20000 euros); Gladys-en Leiboa, de La Tentación Prod., S. A. 
(10000 euros); Una vida no tan simple, de Lamia Producciones (100000 euros); Matrioskas de Solax Company Microop. (35000 euros); Ama-das, de En Buen Sitio Prod. S. L. (48 000 euros); y Ofrenda a la tormenta, de Mantecadas Salazar AIE (52 779,68 euros).

Para la disciplina de Cortometrajes Iris, de The Visible Man, S. L. (25 000 euros), Herdoilduraren gogoa, de Xabier Iriguíbel Úriz (18660 euros); Mendiak -1976-, de Luis Arrieta Etxeberria (11596 euros); No sex for fish, de Pimu y Ruiz A. VisualC (15677,30 euros); Amanece la noche más larga, de Arquetipo Comunicación y New Gravity Laws S. L. (18628,8 euros en total); y 10437,90 euros para dos proyectos más. En el desarrollo de cine por venir: Estrellas Polares, de Ainara Vera (6700 euros); Free my town, de Kanaki Films S. L. (9500 euros); y Ojalá..., de Demiranda Studio, S. L. (3800 euros).

\section{Otros hitos remarcables}

Se celebró la primera edición del Navarra International Film Festival (NIFF) como un espacio de crítica, denuncia, impacto y crecimiento social a través de la difusión y promoción del cine. Tal y como recogen sus impulsores nace con la intención de provocar, de sacar a debate los temas que se ocultan bajo las apariencias, y enfrentar al público con las realidades sociales que muestran a cada individuo como parte de los que nos hace ser complejos. En 2019 las obras destacadas y premiadas de este encuentro cinematográfico fueron Melitón de Oro a la Mejor Obra Audiovisual, dotado con 2000 euros, para Con los ojos abiertos de María Monreal Otano y Melitón de Plata a la Mejor Dirección, dotado con 1000 euros, para el proyecto de los navarros Natxo Leuza y Patricia Irurzun por su trabajo en Born in Gambia.

Al hilo de este premio, cabe destacar Born in Gambia como uno de los más exitosos en cuánto a cortometraje de 2019 del estado español. Seleccionado en cincuenta y tres festivales nacionales e internacionales con premios en veintidós de ellos. De entre ellos se pueden destacar los ganados en New Italians, Jury Award Short Doc Section; Best Short Doc Sole Luna-A Bridge Between Cultures Award, Sole Luna Festival; Mejor cortometraje documental y premio del público al mejor documental del Festival de Cine de Lanzarote o Best Doc Short en Queens World Film Festival.

En otros festivales y premios también tuvo representación el cine navarro. En la 67 Edición del Festival de Cine de San Sebastian Helena Taberna con Varados y Maddi Barber -Urpena Lurra- así como Txepe Lara, que fue homenajeado. También estuvo presente $E l$ Infierno de Raúl de la Fuente, quien también optaría al Goya al Mejor corto Documental, junto con el navarro nominado al Goya a la Dirección Artística Mikel Serrano Lecea.

\section{CLIMATOLOGIA FAVORABLE}

\section{Incentivo fiscal consolidado}

Desde 2014 el incentivo fiscal en Navarra no para de variar y crecer y transformarse para adecuarse a un mayor control de Hacienda y una adecuación en los términos y de- 
talles. Por ello, la «participación en producciones cinematográficas y series audiovisuales», con rasgos similares a los de la financiación de proyectos de I+D+I, se encuentra ya en fase de consolidación de este formato para la generación de producciones audiovisuales en Navarra a la que se han acogido muchos proyectos audiovisuales.

El financiador navarro que realice una aportación a fondo perdido destinada a la realización de producciones españolas de largometrajes y de series audiovisuales de ficción, animación o documental, tendrá derecho a la totalidad de la deducción que hubiera podido generar el contribuyente realizador de la producción. La rentabilidad fiscal de la deducción se limita al importe resultante de multiplicar por 1,25 la suma de las cantidades desembolsadas para la financiación del proyecto. Y el exceso de deducción que pueda resultar por la referida limitación podrá ser aplicado por la productora.

Manteniéndose los ajustes realizados a finales del 2018: deducción del $35 \%$ sobre las inversiones realizadas en producciones, se eleva del 25 al $40 \%$ el porcentaje de inversión total que será necesario realizar en Navarra, se establece un límite de deducción de tres millones de euros y se elimina la posibilidad de articular las producciones a través de agrupaciones de interés económico.

\section{La unión hace la fuerza: Napar y CLAVNA}

Napar, la Asociación de Productoras Audiovisuales de Navarra, cuenta en total con 35 asociados -18 son empresas y 17 profesionales autónomos-.

Con el fin de alcanzar los objetivos definidos para 2019 y teniendo en cuenta la realidad cambiante de la escena audiovisual navarra, Napar desarrolló su programa de actividades. Pudiendo destacar: «Hablamos con...» encuentros profesionales con la industria Gerardo Herrero, Cristina Marinero, Inti Cordera, Antonio Resines o Aintzane Pérez del Palomar

Con participación en más de diez festivales: desarrollaron actividades profesionales en el marco de algunos (Punto de Vista, NIFF, Zinetika, FICBE, Opera Prima de Tudela); SSIFF, Festival de Hendaia, Festival de Cine de Zaragoza; Jurado en Navarra, Tierra de Cine; Jurado Lab me cracy; Jurado en Zinetika; Mesa sobre incentivación fiscal en marzo en San Sebastian (IBAIA); Panel de televisiones regionales en el marco de Conecta Fiction y el fomento del asociacionismo.

De la colaboración - previamente mencionada- con la Filmoteca de Navarra nace el ciclo «Napar en la Filmoteca». Ciclo que consiste en proyectar producciones de los socios para los socios y para los usuarios de la Filmoteca creando así un espacio en el que compartir la experiencia de las películas.

Además, por la naturaleza del producto desarrollado por el sector se ha detectado como interesante la asociación a una entidad de gestión de derechos de propiedad Intelectual y de autoría, como es Intangia, para poder dar a los socios y socias de Napar un servicio de amparo y consejo legal en esta materia. 
Además, Napar ha pasado a formar parte de la Federación PIAF (Productoras Independientes Audiovisuales Federadas) con el objetivo de tener presencia en espacios supraregionales. Con esa intención asociativa Napar ha estado desde el comienzo apoyando y aportando el nacimiento y la consecución del Clúster Audiovisual Navarro, CLAVNA. Como socio fundador, la aportación de Napar a CLAVNA -tanto económica como de soporte personal y recursos técnicos- sigue siendo una constante importante en el día a día de esta asociación.

CLAVNA cuenta actualmente con veintidós socios. Pueden formar parte del Clúster empresas o profesionales, así como otras asociaciones, sociedades, fundaciones o federaciones integradas en el sector audiovisual y sectores afines o tractores que tengan su domicilio social o fiscal en Navarra o que desarrollen su labor en la Comunidad Foral.

Desde el clúster audiovisual se han apoyado programas de acciones de sensibilización y comunicación como «Zinematechna» de Aditech, «Lo que viene» en colaboración con Consorcio Eder, Navarra International Film Festival, Estudios Melitón, Bienal de Arquitectura Latinoamericana (BAL), Animatic con Fundación Caja Navarra o DocsMX.

Además, es un colaborador y financiador junto con NFC de Navarrafilmindustry. com. Ha desarrollado mesas de trabajo como «Turismo de Cine», Observatorio de Incer o de Animación. En 2019 ha impulsado la creación de un Hub Audiovisual cuyo lanzamiento está previsto para 2021.

Involucrado e impulsor del Programa «Animate» con 28 acciones formativas, más de 30 profesores y 100 alumnos en programas intensivos para el programa de animación en 3D. Acciones que han sido causantes de la ampliación como opción universitaria en Navarra en el centro Creanavarra, de estudios superiores de diseño -estudios oficiales de animación- ante el aumento de creaciones audiovisuales en la comunidad y demanda de profesionales con grado en Animación y Efectos Visuales y el máster en 3D para Producciones Cinematográficas.

Fue promotor e impulsor del evento que se celebró en Pamplona en 2019 Conecta Fiction que cuenta con el apoyo del Gobierno de Navarra a través de las empresas públicas Sodena (Sociedad de Desarrollo de Navarra) y NICDO (Navarra de Infraestructuras de Cultura, Deporte y Ocio). También colabora la Fundación SGAE.

\section{Conecta Fiction}

En 2019 se celebró en Pamplona, Baluarte, la 3. . edición de Conecta Fiction. Una iniciativa que, como destaca su directora general Géraldine Gonard, es de carácter internacional y quiere fomentar el networking, la coproducción de ficción televisiva y el intercambio de talento entre Europa, América Latina y América del Norte. Para el Gobierno de Navarra quiere ser un impulsor de sinergias que posibiliten la creación de un tejido empresarial audiovisual propio, capaz de realizar los procesos de posproducción con profesionales navarros. 
Uno de los objetivos que el Gobierno de Navarra se ha fijado en torno a Conecta Fiction es el de que sirva para generar sinergias que propicien la creación de un tejido empresarial audiovisual propio. Además de atraer rodajes, se pretende contar con industrias que posibiliten que los procesos de posproducción se realicen también en Navarra contando con profesionales navarros.

Con aproximadamente 600 participantes, ejecutivos/as y creativos que buscaron para encontrar financiación y producir proyectos de televisión, así como aprender e intercambiar ideas y establecer alianzas a largo plazo. Con plataformas como Netflix o HBO entre los asistentes.

\section{ASTILLERO}

Parece que el barco de la industria del cine entra en reparación. Con un 2019 lleno de rutas, acuerdos comerciales y sinergias que consolidaron el territorio Navarra como referente audiovisual de calidad. Con eventos como Conecta Fiction que han reivindicado el espacio navarro como foro de talento y carácter; la inauguración de Estudios Melitón que aportan plató de interiores que hace que las producciones se queden más tiempo; las ayudas públicas que aumentaron su dotación y artistas navarros como Natxo Leuza, Maddi Barber, Helena Taberna o Raúl de la Fuente que estrenaron y recogieron premios en festivales nacionales e internacionales. El territorio navarro acogió un centenar de producciones en el año más productivo de todo el lustro. Todo parecía con el mar en calma. Pero era ficción: el mar de fondo estaba ahí y toca amarrar en buen puerto y reconducir formas, estrategias. Parece que habrá que reparar piezas. Van a cambiar las formas de rodar, viajar y hacer los encuentros cinematográficos. Y rodarlo todo. Para dejar memoria audiovisual de esta etapa en el cuaderno de bitácora.

\section{LISTA DE REFERENCIAS}

www.navarra.es

https://www.conectafiction.com

http://www.nicdo.es

https://navarrafilm.com

Navarra Film Commission (Sara Sevilla) https://navarrafilmindustry.com

Informe Napar_Junta Directiva

Informe Clavna_Junta Directiva

Nota de prensa de estudios Melitón

Opera Prima Tudela_Julio Mazarico

https://www.navarra.es/es/gobierno-de-navarra/departamento-de-desarrollo-economi-

Diario de Navarra co-y-empresarial

Diario de Noticias

https://www.navarra.es/home_es/Servicios/ficha/8120/Convocatoria-de-ayudas-al-cine-2019-Generazinema

268 Príncipe de Viana (PV), 276, urtarrila-apirila, 2020, 259-268 ISSN: 0032-8472 | ISSN-e: 2530-5824 | ISSN-L: 0032-8472 